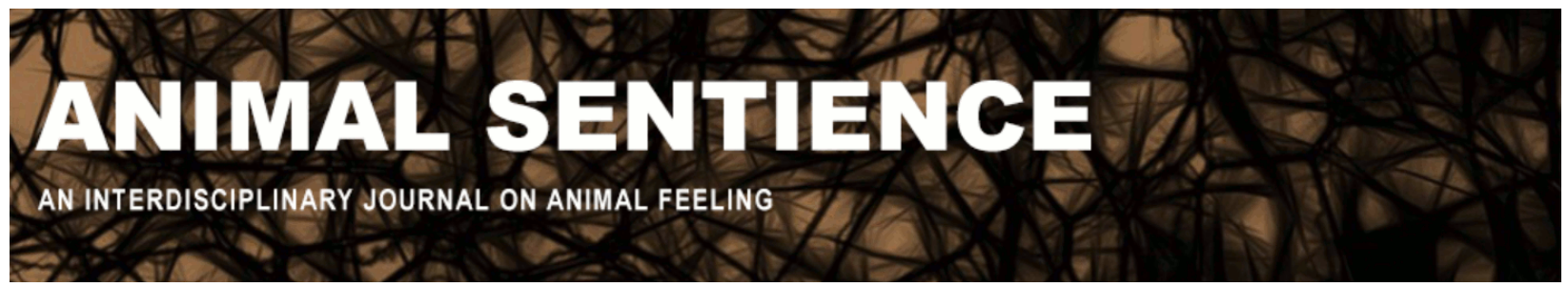

Vallortigara, Giorgio (2020) Lessons from miniature brains: Cognition cheap, memory expensive (sentience linked to active movement?). Animal Sentience 29(17)

DOI: $10.51291 / 2377-7478.1603$

Date of submission: $2020-06-28$

Date of acceptance: 2020-06-30

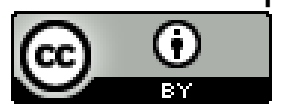

This article has appeared in the journal Animal

Sentience, a peer-reviewed journal on animal

cognition and feeling. It has been made open access,

free for all, by WellBeing International and deposited

in the WBI Studies Repository. For more information,

please contact

wbisr-info@wellbeingintl.org.

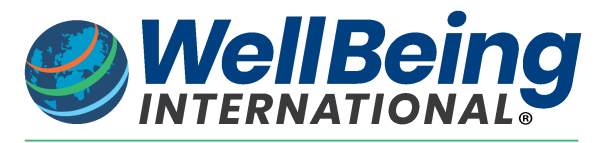

SOLUTIONS FOR PEOPLE, ANIMALS AND ENVIRONMENT 


\title{
Lessons from miniature brains: Cognition cheap, memory expensive (sentience linked to active movement?)
}

Commentary on Mikhalevich \& Powell on Invertebrate Minds

\author{
Giorgio Vallortigara \\ Centre for Mind/Brain Sciences, University of Trento, Italy
}

\begin{abstract}
Studies on invertebrate minds suggest that the neural machinery for basic cognition is cheap, and that bigger brains are probably associated with greater memory storage rather than more advanced cognition. Sentience may be linked to feedforward mechanisms (Reafferenzprinzip) that allow organisms with active movement to distinguish active and passive sensing. Invertebrates may offer special opportunities for testing these hypotheses.
\end{abstract}

Giorgio Vallortigara, professor of Neuroscience, Centre for Mind/Brain Sciences, University of Trento, studies space, number and object cognition, and brain asymmetry in a comparative and evolutionary perspective. He is the author of more than 300 scientific papers on these topics, and the recipient of Geoffroy Saint Hilaire Prize for Ethology and Doctor Rerum Naturalium Honoris Causa for outstanding achievements in psychobiology

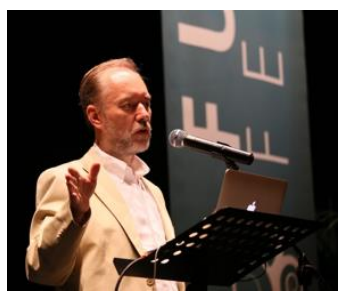
(Ruhr University). Website

I would like to contribute two brief comments inspired by this mostly welcome and timely target article by Mikhalevich and Powell (2020) (M\&P) about invertebrate cognition and welfare.

1. Brain Structure and Cognitive Complexity. From time to time, specific features of the brain are used to claim some sort of human (or primate, or mammalian, or vertebrate) superiority (Chapman and Huffman 2018). A case in point with which I am very familiar is brain asymmetry: the differences in function between the left and right side of the brain. As with similar uniqueness claims for other structures (e.g., von Economo neurons, Allman et al. 2002; frontal lobes, Barton and Venditti 2013; hippocampus minor, Gross 1993), there has been a rise, a decline, and eventually a lapse of the uniqueness hypothesis for brain asymmetry. At first it has been argued that it was unique to humans and associated with language and higher cognitive abilities (for a historical account, see Corballis, 2020). Then, it was slowly recognized that asymmetry is quite widespread among vertebrates, even if they do not have anything equivalent to human language (e.g., MacNeilage, Rogers and Vallortigara, 2009; Rogers, Vallortigara and Andrew, 2013). Finally, more recently, it has become apparent that brain asymmetry is observed also in invertebrates (review in Frasnelli et al., 2012), most notably in insects like bees (Frasnelli et al., 2014) but also in C. elegans worms, who have only 300 neurons (Vidal and Hobert, 2017).

One crucial challenge, however, would be to determine whether this basic brain design, with its important consequences for cognition (Vallortigara and Rogers, 2020), evolved separately in different taxonomic groups. (This would be interesting because it would suggest that in order to have cognition, a convergence on some details of the evolution of nervous systems is needed.) Or is there some form of deep homology at work here? 
Although the idea that lateralization in vertebrate and invertebrate species is analogous and not homologous sounds plausible, there is some evidence that the same genes that influence lateralization are present in both protostomes and deuterostomes (Rogers and Vallortigara, 2015). For example, Grande and Patel (2009) discovered that an orthologue of the signaling molecule Nodal, which plays a crucial role in the development of lateralization in vertebrates, is also present in a non-deuterostome, a snail. Genes expressed in left-right asymmetry in C. elegans are known to have orthologues in vertebrates (Hsieh et al., 2014); and genes like the Hox gene (Cotelis et al., 2013) seem to be common determinants of gut asymmetry in both invertebrates and vertebrates (Géminard et al., 2014).

2. Advanced Cognition in Miniature Brains. Evidence of advanced cognition is emerging from studies on arthropods such as bees (e.g., Solvi et al., 2020; Bortot et al., 2020; Giurfa et al., 2001) whose brains are tiny in size and volume but also in their number of neurons (Chittka and Niven, 2009). There is parallel evidence from artificial neural networks showing that allegedly complex cognitive feats such as numerosity discrimination (e.g., Vasas and Chittka, 2019) and face recognition (Dyer et al., 2005) can actually be accomplished by neural nets composed of a modest number of "neurons" (e.g., a couple of hundred neurons suffices for face discrimination; Aitkenhead et al., 2003).

It seems to me that the lesson we must take home from all this is that cognition is cheap. But if so, why do some animals have huge numbers of neurons? Well, I believe it is simply for the purposes of memory. Big brains are large and have higher numbers of neurons because of memory needs, not Central Processing Unit (CPU) needs. Face recognition is a case in point: Few neurons are needed to discriminate faces. Bees (unlike paper wasps, who have adaptive specializations for it; Sheehan and Tibbetts, 2011) can do face recognition easily (Dyer et al., 2005). Mammals and birds need large number of neurons to store a large number of faces in their memories for individual recognition purposes (Jenkins et al., 2018). Thus, it is not a matter of cleverness - just memory storage and recall. The implications for our conception of the minds of invertebrates such as insects are quite obvious: these animals may have miniature brains but not necessarily miniature minds.

I am afraid, however, that I am not convinced that this evidence has implications for ethics, for as I argued for other species (Vallortigara, 2017), sentience is different from cognition. The presence of higher-level cognition does not make it more (or less) likely that sentience is present too. I have argued (Vallortigara, 2020) that sentience emerged in animals from adjustments in the mechanisms associated with the so-called Reafferenzprinzip (von Holst and Mittelstaedt, 1950). Reafference may provide the mechanistic basis for the distinction, first proposed by Thomas Reid (1785/1997) and then beautifully developed by Nicholas Humphrey (1992), between sensation ("what is happening to me") and perception ("what is happening out there"). Invertebrates can provide interesting ways to test these conjectures by comparisons with organisms that are unlikely to be sentient (corals, for example, as suggested by M\&P). We know that cellular mechanisms for corollary discharge exist and are well-studied in insects (Poulet and Hedwig, 2006). As far as I know, they have no obvious equivalent in, say, plants - or if they do, a major difference would be associated with the extended temporal delay of feedforward mechanisms associated with plant movement (i.e., growth) (cf. Yokawa \& Baluška, 2018). 


\section{References}

Aitkenhead, M.J., McDonald, A.J.S. (2003). A neural network face recognition system. Engineering Applications of Artificial Intelligence, 16: 167-176.

Allman, J., Hakeem, A., Watson, K. (2002). Two phylogenetic specializations in the human brain. Neuroscientist, 8: 335-346.

Barton, R.A., Venditti, C. (2013). Human frontal lobes are not relatively large. Proceedings of the National Academy of Science USA, 110: 9001-9006.

Bortot, M., Stancher, G., Vallortigara, G. (2020). Transfer from number to size reveals abstract coding of magnitude in honeybees. iScience, 23: 101122.

Chapman, C.A., Huffman, M.A. (2018). Why do we want to think humans are different? Animal Sentience 23(1).

Chittka L., Niven, J. (2009). Are bigger brains better? Current Biology, 19: R995-R1008.

Corballis, M.C. (2020). Humanity and the left hemisphere: The story of half a brain. Laterality, in press.

Cotelis, J-B., Géminard, C., Spéder, P., Magali, S., Petzoldt, A.G., Noselli, S. (2013). Drosophila left/right asymmetry establishment is controlled by the Hox gene abdominal-B. Developmental Cell, 24: 89-97.

Dyer, A. G., Neumeyer, C., Chittka, L. (2005). Honeybee (Apis mellifera) vision can discriminate between and recognise images of human faces. Journal of Experimental Biology, 208: 47094714.

Frasnelli, E., Haase, A., Rigosi, E., Anfora, G., Rogers, L.J., Vallortigara, G. (2014). The bee as a model to investigate brain and behavioural asymmetries. Insects, 5: 120-138.

Frasnelli, E., Vallortigara, G., Rogers, L.J. (2012). Left-right asymmetries of behaviour and nervous system in invertebrates. Neuroscience and Biobehavioral Reviews, 36: 1273-1291.

Géminard, C., Gonzales-Morales, N., Coutelis, J-B., Noselli, S. (2014). The myosin ID pathway and left-right asymmetry in Drosophila. Genesis, 52: 471-480.

Giurfa, M., Zhang, S., Jenett, A., Menzel, R., Srinivasan, M.V. (2001). The concepts of "Sameness" and "Difference" in an Insect. Nature, 410: 930-933.

Grande, C., Patel, N.H. (2009). Nodal signalling is involved in left-right asymmetry in snails. Nature, 457: 1007-1011.

Gross, C. G. (1993). Hippocampus minor and man's place in nature: A case study in the social construction of neuroanatomy. Hippocampus, 3: 403-415.

Hsieh, Y-W., Alqadah, A., Chuang, C-F. (2014). Asymmetric neural development in the Caenorhabditis elegans olfactory system. Genesis, 52: 544-554.

Humphrey, N. (1992). A History of the Mind. Chatto \& Windus, London.

Jenkins, R., Dowsett, A.J., Burton, A.M. (2018). How many faces do people know? Proceedings of the Royal Society of London B, 285: 20181319.

Macneilage, P.F., Rogers, L.J., Vallortigara, G. (2009). Origins of the left and right brain. Scientific American, 301: 60-67.

Mikhalevich, I., Powell, R. (2020). Minds without spines: Evolutionarily inclusive animal ethics. Animal Sentience 29(1).

Poulet, J.F.A., Hedwig, B. (2006). The cellular basis of a corollary discharge. Science, 311: 518522. 
Reid, T. (1785/1997). An Inquiry into the Human Mind on the Principles of Common Sense. Ed. D. R. Brookes. Edinburgh: Edinburgh University Press.

Rogers, L.J., Vallortigara, G. (2015). When and why did brains break symmetry? Symmetry, 7: 2181-2194.

Rogers, L.J., Vallortigara, G., Andrew, R.J. (2013). Divided Brains. The Biology and Behaviour of Brain Asymmetries. Cambridge University Press, New York.

Sheehan, M.J., Tibbetts, E.A. (2011). Specialized face learning is associated with individual recognition in paper wasps. Science, 334: 1272-1275.

Solvi, C., Gutierrez Al-Khudhairy, S., Chittka, L. (2020). Bumble bees display cross-modal object recognition between visual and tactile senses. Science, 367: 910-912.

Vallortigara G. (2017). Sentience does not require "higher" cognition. Animal Sentience 17(6).

Vallortigara, G. (2020). Pensieri della mosca con la testa storta (Thoughts of a fly with a twisted head). Adelphi, Milano, in press.

Vallortigara, G., Rogers, L.J. (2020). A function for the bicameral mind. Cortex, 124: 274-285.

Vasas V., Chittka, L. (2019). Insect-inspired sequential inspection strategy enables an artificial network of four neurons to estimate numerosity. iScience, 11: 85-92.

Vidal, B., Hobert, O. (2017). Methods to study nervous system laterality in the Caenorhabditis elegans model system. In Lateralized Brain Functions (Eds. Rogers, L.J., Vallortigara, G.), pp. 591-608. Springer, New York.

von Holst, E., Mittelstaedt, H. (1950). Das Reafferenzprinzip. Naturwissenschaften, 37: 464-476. Wentworth, S.L., Muntz, W.R.A. (1989). Asymmetries in the sense organs and central nervous system of the squid Histioteuthis. Journal of Zoolology, 219: 607-619.

Yokawa, K., Baluška, F. (2018). Fish and plant sentience: Anesthetized plants and fishes cannot respond to stimuli. Animal Sentience 21(6). 